\title{
Qualidade fisiológica de sementes de Physalis peruviana sob condições de estresse
}

\section{hídrico}

\author{
Physiological quality of Physalis peruviana seeds under water stress conditions \\ Calidad fisiológica de semillas de Physalis peruviana en condiciones de estrés hídrico
}

Recebido: 21/01/2022 | Revisado: 25/01/2022 | Aceito: 29/01/2022 | Publicado: 31/01/2022

Valmira Hoste Dutra
ORCID: https://orcid.org/0000-0003-1930-3071
Faculdade Univértix, Brasil
E-mail: valmirahoste @ gmail.com
Livia Mara Araujo Amorim
Faculdade Univértix, Brasil
ORCID: https://orcid.org/0000-0002-385-6290
E-mail: liviaamorim24@gmail.com
Ana Maria Guimarães Bernardo
ORCID: https://orcid.org/0000-0002-3685-4273
E-mail: ana.bernardo@ifap.edu.br
Ediane Conceição Alves
Instituto Federal de Educação, Ciência e Tecologia do Amapá, Brasil
ORCID: https://orcid.org/0000-0003-4359-5932
Universidade Federal de Viçosa, Brasil
E-mail: ediannealvess@ gmail.com
Cleber Macedo de Oliveira
ORCID: https://orcid.org/0000-0003-0075-3160
E-mail: cleber.oliveira@ @ifap.edu.br
Instituto Federal de Educação, Ciência e Tecnogia do Amá, Brasil
Denise Cunha Fernandes dos Santos Dias
ORCID: https://orcid.org/0000-0002-0596-2490
Universidade Federal de Viçosa, Brasil
E-mail: dcdias@ ufv.br

\begin{abstract}
Resumo
Physalis peruviana é uma planta herbácea, arbustiva e perene, pertence à família Solanaceae. Os seus frutos apresentam alto valor nutricional e propriedades medicinais. Com a crescente importância e sua propagação ser sexuada, buscam-se sementes de alta qualidade. A fase inicial do desenvolvimento de plântulas é delicada e de grande importância; em campo, estão sujeitas a diversos fatores que podem interferir no seu desenvolvimento, como o estresse hídrico. Com isso, objetivou-se avaliar o efeito do estresse hídrico na qualidade fisiológica de sementes de P. peruviana. As sementes foram submetidas ao teste de envelhecimento acelerado conduzido a $41{ }^{\circ} \mathrm{C}$ e $100 \%$ UR por 0 ; 48; 72 e 96h para obtenção de diferentes lotes. O estresse hídrico foi induzido com PEG-6000 com quatro potenciais osmótico, 0,0 (controle); -0,2; -0,4 e -0,6 MPa. Avaliou-se a germinação e o vigor das sementes (primeira contagem, comprimento da parte aérea e da raiz). O envelhecimento acelerado reduziu a porcentagem de germinação à medida que aumentou o tempo de exposição. Conclui-se que os lotes de sementes de P. peruviana de maior qualidade fisiológica apesentaram melhor desempenho sob estresse hídrico induzido por PEG 6000 até o potencial -0,2 MPa. A restrição hídrica provocou um menor crescimento de plântulas da parte área, no entanto, quando as sementes foram submetidas ao potencial - $0,2 \mathrm{MPa}$, verificou-se um aumento no comprimento radicular.
\end{abstract}

Palavras-chave: Propagação sexuada; Germinação; Potencial osmótico; Polietileno glicol.

\begin{abstract}
Physalis peruviana is a herbaceous, shrubby and perennial plant belonging to the Solanaceae family. Its fruits have high nutritional value and medicinal properties. Due to its growing importance and propagation being sexual highquality seeds are sought. The early stage of seedling development is delicate and of great importance; in the field they are subjected to several factors that may interfere with their development such as water stress. The aim was to evaluate the effect of water stress on physiological quality of $P$. peruviana seeds. Seeds were submitted to accelerated aging test conducted at $41{ }^{\circ} \mathrm{C}$ and $100 \% \mathrm{RH}$ for $0 ; 48 ; 72$ and $96 \mathrm{~h}$ in order to obtain different batches. Water stress was induced with PEG-6000 with four osmotic potentials: 0.0 (control); $-0.2 ;-0.4$ and $-0.6 \mathrm{MPa}$. Seed germination and vigor were evaluated (first count, shoot and root length). Accelerated aging reduced germination percentage as exposure time increased. It is concluded that seed batches of $P$. peruviana with the highest physiological quality showed better performance under water stress induced by PEG 6000 up to the potential $-0.2 \mathrm{MPa}$. Water restriction
\end{abstract}


caused a smaller growth of seedlings in the aerial part however, when seeds were submitted to the $-0.2 \mathrm{MPa}$ potential there was an increase in root length.

Keywords: Sexual propagation; Germination; Osmotic potential; Polyethylene glycol.

\section{Resumen}

Physalis peruviana es una planta herbácea, arbustiva y perene, perteneciente a la familia Solanaceae. Sus frutos tienen un alto valor nutricional y propiedades medicinales. Con la creciente importancia y siendo su propagación sexual, se buscan semillas de alta calidad. La fase inicial del desarrollo de plántulas es delicada y de gran importancia; en campo, están sujetas a varios factores que pueden interferir en su desarrollo, como el estrés hídrico. Así, el objetivo fue evaluar el efecto del estrés hídrico sobre la calidad fisiológica de semillas de P. peruviana. Las semillas se sometieron a la prueba de envejecimiento acelerado realizada a $41^{\circ} \mathrm{C}$ y $100 \% \mathrm{HR}$ por $0 ; 48 ; 72$ y $96 \mathrm{~h}$ para obtener diferentes lotes. El estrés hídrico se indujo con PEG-6000 con cuatro potenciales osmóticos, 0,0 (control); -0,2; -0,4 y $-0,6 \mathrm{MPa}$. Se evaluó la germinación y el vigor de las semillas (primer conteo, longitud de la parte aérea y raíces). El envejecimiento acelerado redujo el porcentaje de germinación a medida que aumentaba el tiempo de exposición. Se concluyó que los lotes de semilla de P. peruviana de mayor calidad fisiológica presentaron mejor rendimiento sobre estrés hídrico inducido por PEG 6000 hasta el potencial $-0,2 \mathrm{MPa}$. La restricción hídrica provocó un menor crecimiento de plántulas de la parte aérea, sin embargo, cuando las semillas fueron sometidas al potencial $-0,2 \mathrm{MPa}$, hubo un aumento en la longitud de raíces.

Palabras clave: Propagación sexual; Germinación; Potencial Osmótico; Polietileno Glicol.

\section{Introdução}

Physalis peruviana L. pertence à família Solanaceae, com sua origem na Amazônia e nos Andes. Como todas de sua família, trata-se de uma planta herbácea, arbustiva e perene, apesar de ser cultivada como anual, de acordo com a região onde a cultura é implantada. O seu cultivo é considerado bastante simples (Rufato et al., 2013). Quanto ao manejo, é semelhante ao utilizado para a cultura do tomateiro, havendo a necessidade de tutoramento, adubação, irrigação, controle de pragas (Rufato et al., 2013). É caracterizada como uma planta arbustiva e rústica, que pode atingir uma altura de até $2 \mathrm{~m}$ (Chaves et al., 2005), com uma produção aproximada de 2 a $3 \mathrm{~kg}$ de fruto por planta em um ciclo (Fischer \& Martines, 1999). Zapata et al. (2002) apresentam que após o transplantio, a colheita se inicia após 3 a cinco meses, e a planta com tratos culturais adequados pode produzir frutos de boa qualidade por até um ano. Segundo Rutz et al. (2012) o consumo de Physalis sp. é muito importante devido seu alto valor nutricional, com diversas propriedades medicinais, ainda de acordo com Rufato et al. (2013) o fruto é rico em vitaminas A, C, fósforo e ferro. Os frutos contêm importantes componentes químicos que agem no sistema imunológico e substâncias antioxidantes que são fundamentais para o organismo humano, entre elas, podemos citar os flavonóides.

A propagação de P. peruviana é feita de forma sexuada, isto é, por sementes. De acordo com Black e El Hadi (1992), o processo de germinação de uma semente apresenta três fases: i) embebição; ii) pausa para ação de processos metabólicos; e iii) desenvolvimento inicial com a emergência da radícula. Em todos os processos, é fundamental a presença de água. Silva et al. (2011) atestam que o processo de plantio é o momento em que as sementes estão sujeitas ao maior número de adversidades ambientais, tais como déficit hídrico, variação na temperatura, competição com plantas espontâneas, além de estarem sujeitas ao ataque de pragas e doenças. A fase inicial do desenvolvimento de plântulas é a mais sensível e de grande importância para o estabelecimento da planta que estão sujeitas a influência de inúmeros fatores bióticos e abióticos, o que pode interferir em seu desenvolvimento, um desses fatores mais importantes é o estresse hídrico sofrido pela semente logo após a distribuição das mesmas no campo. Além disso, a água no solo é considerada um fator limitante para o crescimento e o desenvolvimento das espécies vegetais, podendo alterar diretamente a produtividade final. Com isso, é imprescindível conhecer a fisiologia vegetal e seus mecanismos internos para entender como são afetadas por esse tipo de estresse (Lechinoski et al., 2007).

Pastori e Foyer (2002) concluem que as plantas são capazes de desenvolver mecanismos de proteção que asseguram a sobreviverem às mudanças ambientais por meio da alteração metabólica. De acordo com Sun e Leopold (1997) e Braga (2010), para se ter uma germinação completa das sementes, é imprescindível o fornecimento de água; quando, por algum motivo, as sementes são expostas ao estresse hídrico, estas tendem a ter um aumento dos solutos, alteração do pH intracelular, 
desnaturação das proteínas e até mesmo perda da integridade das membranas e, consequentemente, o número de plântulas deformadas será maior. Adegbuyi et al. (1981) corroboram que o estresse hídrico interfere na velocidade de germinação das sementes, bem como afeta a porcentagem de plântulas normais, sendo esses parâmetros são afetados de acordo com a espécie. Cada espécie tem seu teor de água mínimo no qual as sementes não serão capazes de germinar, principalmente na fase de embebição, fase na qual, quando as sementes são submetidas a potenciais hídricos muito baixos, afeta diretamente a germinação, podendo até matar o embrião (Hobbs \& Oberndorf, 1972). O déficit hídrico reduz a velocidade de germinação, afetando negativamente a germinação devido ao atraso ou até mesmo a não ocorrência dos processos metabólicos necessários à germinação (Rahimi, 2013). Teixeira et al. (2011) mostraram que o estresse hídrico interfere negativamente na germinação e no vigor das sementes de crambe (Crambe abyssinica), além disso, é sabido que as sementes mais vigorosas são capazes de tolerar condições extremas de estresse hídrico (Hadas, 1977). Vaz-de-Melo et al. (2012) observaram que o estresse hídrico afetou negativamente o crescimento de plântulas e a velocidade de germinação de milho-pipoca.

Diante dessa realidade, muitos estudos são realizados com o objetivo de avaliar os efeitos do estresse hídrico em sementes no desenvolvimento das plântulas de diversas espécies. Por exemplo, os estudos de Costa, Custódio, Machado Neto e Marubayashi (2004) que pesquisaram o efeito do estresse hídrico em sementes de Glycine max (L.) Merr. (soja) com tamanhos diferentes e Vale et al. (2012) estudaram os diferentes genótipos de feijão, classificando-os de acordo com sua tolerância e sensibilidade ao estresse hídrico. Moterle et al. (2006) avaliaram o estresse hídrico e salino na germinação de sementes e emergência de plântulas de milho-pipoca. Basha et al. (2015) observarm o efeito do estresse hídrico induzido por PEG em diferentes concentrações na germinação e no desenvolvimento de plântulas utilizando germoplasma de tomate. O polietileno glicol é muito utilizado para simular o estresse hídrico e o PEG trata-se de um composto químico inerte e não tóxico (Tambelini \& Perez, 1998), e é um composto de alto peso molecular (Nascimento, 1998) com moléculas grandes, e que não são possíveis de serem absorvidas pelas sementes (Villela et al., 1991).

Existem estudos sobre características morfológicas das sementes de Physalis sp. (Souza et al., 2010), em relação à maturação das sementes para identificar o estágio de maturação que apresenta maior qualidade fisiológica (Carvalho et al., 2020) e também pesquisas referente à influência da temperatura, da luz, do tipo de substrato na germinação das sementes (Diniz et al., 2020; Pellizaro et al. 2019) e das condições de armazenamento na germinação de Physalis sp. (Souza et al., 2016). No entanto, não há estudos sobre restrição hídrica envolvendo essa espécie. Com isso, objetivou-se avaliar o efeito do estresse hídrico na qualidade fisiológica de sementes de P. peruviana.

\section{Material e Métodos}

A semeadura das sementes de $P$. peruviana foi realizada em bandejas de isopor sobre o substrato comercial Plantmax $^{\circledR}$, na casa de vegetação da Universidade Federal de Viçosa - Minas Gerais. O transplantio das mudas foi realizado 44 dias após a semeadura (DAS), para vasos de plástico polietileno com capacidade de $5 \mathrm{~L}$, contendo substrato composto da mistura de 2:1 de solo e substrato comercial Tropstrato ${ }^{\circledR}$, respectivamente. A condução desta fase do experimento, transplantio até a coleta dos dados foi realizada em uma casa de vegetação localizada no Córrego Monte Alegre, Fazenda Fortaleza na zona rural de Matipó - Minas Gerais, com as seguintes coordenadas geográficas: latitude 20²0’21,69”S e longitude 42¹6’56,6”O. Após o transplantio, as mudas foram irrigadas mantendo-se o solo próximo à capacidade de campo. Após uma semana do transplantio, foi realizada a adubação com Super Simples (18\% de $\mathrm{P}_{2} \mathrm{O}_{5}$ ), juntamente ao NPK (4-14-8), conforme indicação para a cultura do tomateiro irrigado (Filgueira et al., 1999). Esse processo foi repetido a cada 15 dias até a colheita dos frutos.

Para a condução do presente trabalho, os frutos com coloração verde cana e o cálice verde foram colhidos aos 75 dias após a antese (DAA). Após a colheita, os frutos foram levados para o laboratório, as sementes foram extraídas e dispostas sobre peneiras e submetidas à lavagem em água corrente, até a remoção completa da mucilagem. Posteriormente, essas 
permaneceram dispostas sobre papel toalha, em temperatura ambiente para secagem até aproximadamente $13 \%$ de umidade. Posteriormente, essas sementes foram tratadas com o fungicida Derozal Plus ${ }^{\circledR}$ (Carbendazim $150 \mathrm{~g} / \mathrm{L}+$ Tiram $350 \mathrm{~g} / \mathrm{L}$ ) na dosagem de $200 \mathrm{~mL} .100 \mathrm{Kg}^{-1}$ de sementes.

Em seguida, foi realizado o envelhecimento acelerado conforme metodologia descrita por Oro et al. (2012) e descrita a seguir. As sementes foram distribuídas sobre uma tela acoplada a caixa plástica transparente (gerbox), contendo $40 \mathrm{~mL}$ de água na parte inferior desta. As caixas contendo as sementes foram acondicionadas em câmara de germinação do tipo BOD, a qual foi regulada à temperatura de $41^{\circ} \mathrm{C}$ com fotoperíodo regulado em $8 \mathrm{~h}$ de luz e $16 \mathrm{~h}$ de escuro, permanecendo por $0 ; 48 ; 72$ e 96h. Ao final desses períodos, foram obtidos quatro lotes com diferentes níveis de qualidade fisiológica, denominados lotes $1,2,3$ e 4 , respectivamente.

As sementes obtidas em cada tempo de envelhecimento (lotes) foram mantidas em bandejas em temperatura ambiente até atingirem grau de umidade de aproximadamente de $13 \%$ e em seguida as sementes foram acondicionadas em sacos de papel. Posteriormente, foram submetidas aos tratamentos de estresse hídrico utilizando-se soluções de polietileno glicol-6000 (PEG-6000) nos seguintes potenciais 0,0 (controle); -0,2; -0,4 e -0,6 MPa. Para o preparo das soluções foram utilizadas 0; 119; 178 e $224 \mathrm{~g}$ de PEG 6000. $\mathrm{kg}^{-1}$ de água, conforme o método de Villela, Doni Filho e Sequeira (1991). Para tanto, quatro repetições de 50 sementes foram semeadas sobre duas folhas papel umedecido com cada uma das soluções de PEG-6000 descritas acima em caixas gerbox. Para o umedecimento do papel utilizou-se um volume de solução equivalente a 2,5 vezes o peso do papel seco. As caixas foram mantidas em câmara de germinação do tipo BOD, sob temperatura alternada $\left(20^{\circ}-30^{\circ} \mathrm{C}\right)$ com $8 \mathrm{~h}$ de luz e 16h de escuro, conforme indicado para o teste de germinação da espécie (Brasil, 2009). Foram feitas as seguintes avaliações: primeira contagem de germinação - consistiu do registro da porcentagem de plântulas normais obtidas no $10^{\circ}$ dia após a semeadura; germinação - consistiu do somatório da porcentagem de plântulas normais obtidas aos 10 e 30 dias após a semeadura; comprimento da parte aérea e raiz - as sementes foram distribuídas de forma equidistantes sobre uma linha no terço superior da folha, sobre duas folhas de papel germitest umedecidas com as diferentes concentrações de PEG6000 (como descrito acima) e cobertas por uma terceira folha. Utilizaram-se cinco subamostras de dez sementes oriundas de cada lote. Foram confeccionados rolos os quais foram encaminhados para câmera de germinação. Após 30 dias, o comprimento da raiz e da parte aérea das plântulas foi determinado com auxílio de uma régua graduada em milímetros. Os resultados foram expressos em cm.plântula ${ }^{-1}$.

Análise estatística: o delineamento experimental utilizado foi o inteiramente casualizado (DIC) em esquema fatorial $4 \times 4$ (4 períodos de envelhecimento acelerado - lotes x 4 diferentes potenciais osmóticos) com quatro repetições com 50 sementes por repetição. Os dados obtidos foram submetidos à análise de regressão, no programa estatístico SigmaPlot versão 12.5 (Systat Software, San José, CA, EUA).

\section{Resultados e Discussão}

Pode-se observar que a porcentagem de germinação reduziu progressivamente com o aumento do período de envelhecimento (horas) das sementes, verificando-se valores de germinação de $85 \%$ e $78 \%$ nos períodos compreendidos entre 48 e 72 horas, respectivamente (Figura 1). 
Figura 1. Porcentagem de germinação de sementes de Physalis peruviana submetidas ao envelhecimento acelerado.

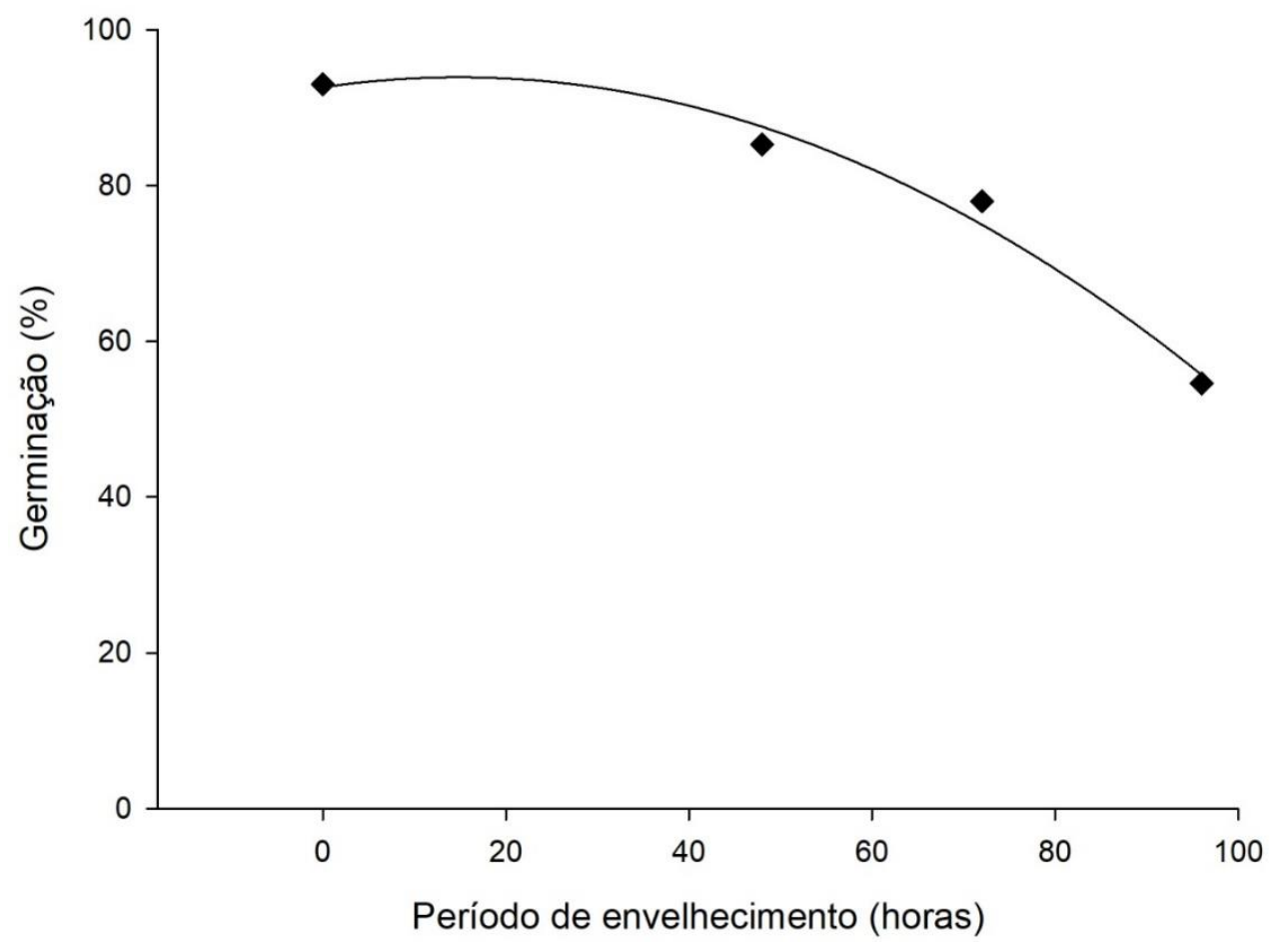

Fonte: Autores (2022).

A redução mais significativa na germinação ocorreu no período de $96 \mathrm{~h}$ de envelhecimento, quando foi obtido o valor de 54\%. Portanto, foi possível a obtenção de lotes com diferentes níveis de qualidade fisiológica. Barbosa, Costa e Sá (2011) analisaram o comportamento de diferentes espécies de oleráceas (couve-flor, berinjela, alface, rúcula, brócolis e tomate), no qual verificaram que o envelhecimento acelerado afeta as sementes à medida que aumenta o tempo de exposição, além de afetar a formação de mudas de alface, tomate e couve-flor.

Os diferentes lotes de sementes de $P$. peruviana apresentaram redução na porcentagem de germinação de acordo com o aumento das concentrações de PEG-6000. Adicionalmente, observou-se que todos os lotes no teste de germinação apresentaram alta porcentagem de germinação até o potencial -0,2 MPa. Já nos demais potenciais osmóticos (-0,4 e -0,6 MPa), a porcentagem de germinação reduziu gradativamente (Figura 2). 
Figura 2. Porcentagem de germinação de sementes de Physalis peruviana submetidas a diferentes estresses hídricos, induzido com PEG-6000.

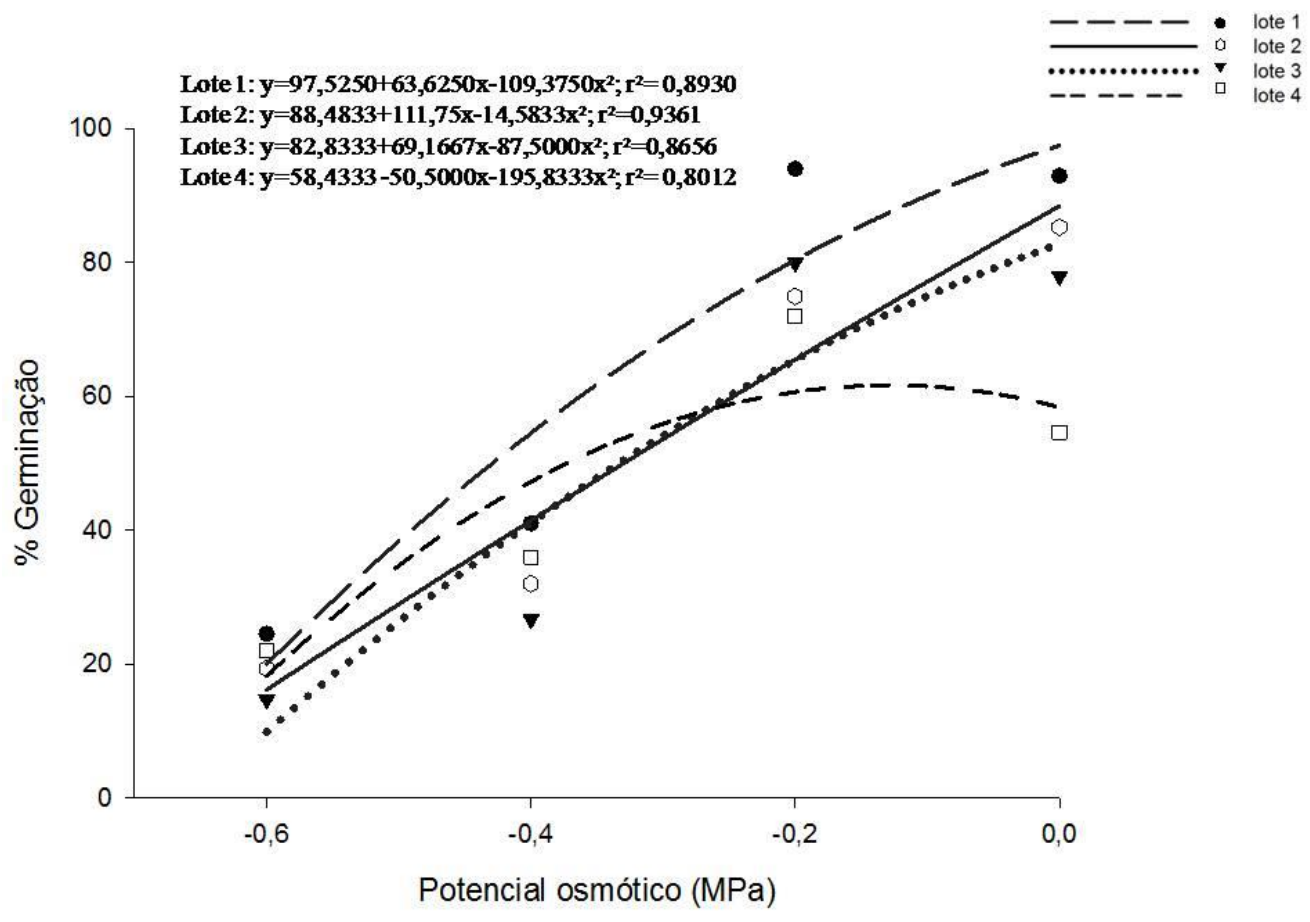

Fonte: Autores (2022).

Resultados similares foram observados por Basha et al. (2015), que encontraram, em diferentes cultivares de tomate, uma redução na taxa e no desenvolvimento de plântulas em condições de déficit hídrico. Esse decréscimo na germinação pode estar relacionado ao fato de que o PEG apresenta alta viscosidade, impedindo que as sementes absorvam água e, como consequência ocasionou a redução do seu potencial germinativo (Yoon et al., 1997).

Na primeira contagem, os lotes 1 e 2 apresentaram o mesmo comportamento, no qual a porcentagem de germinação diminuiu progressivamente de acordo com o aumento das concentrações de PEG-6000. No entanto, o lote 4 comportou-se diferente, uma vez que a germinação foi maior no controle $(0,0)$ do que nos demais potenciais. Já no lote 3 , não houve germinação no controle, porém nos potenciais -0,2 e -0,4 MPa teve maior porcentagem germinação; já a $-0,6 \mathrm{MPa}$ a porcentagem de germinação reduziu (Figura 3). 
Figura 3. Porcentagem de germinação (plântulas normais) na primeira contagem de sementes de Physalis peruviana submetidas a diferentes estresses hídricos, induzidas com PEG-6000.

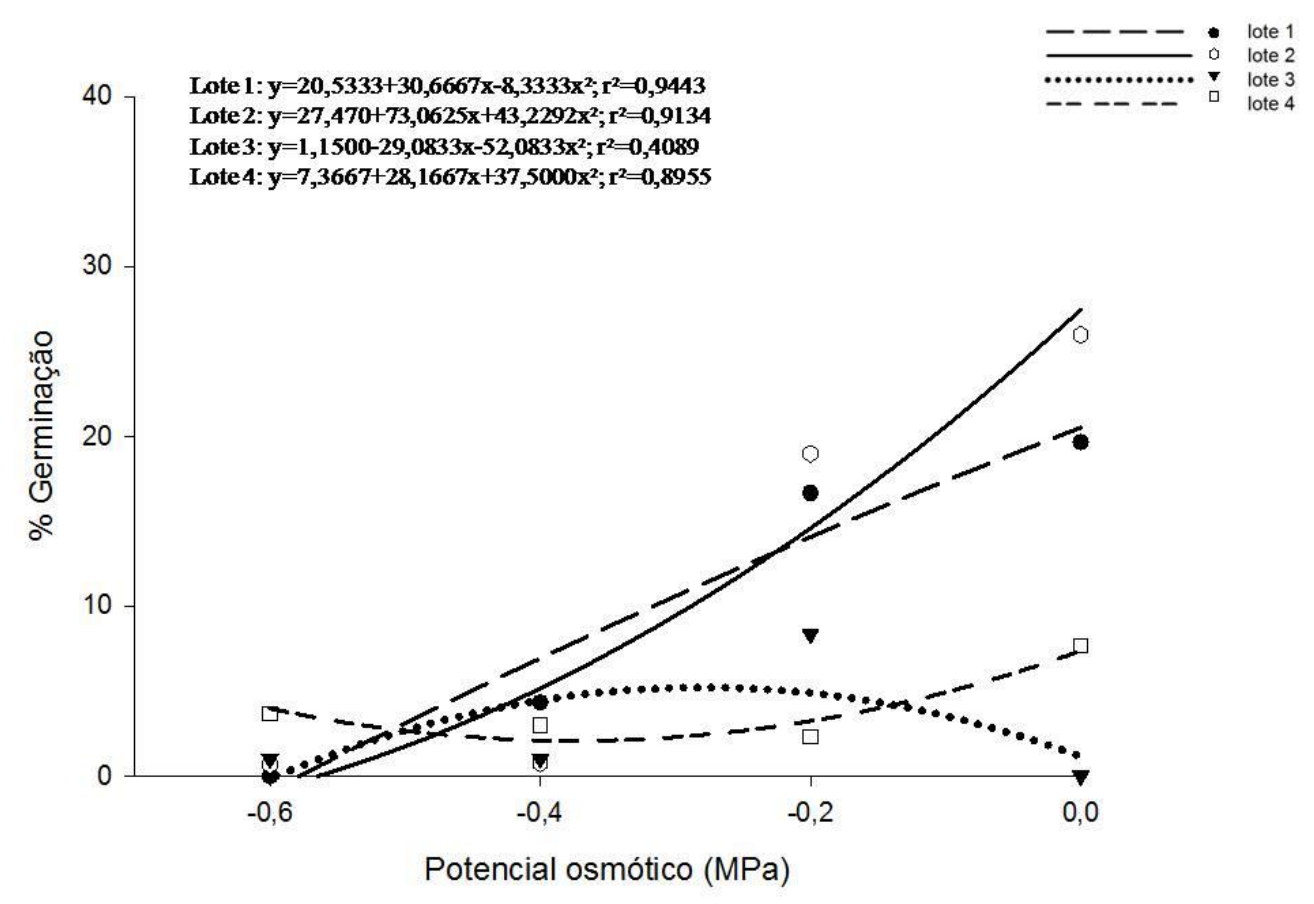

Fonte: Autores (2022).

Moraes e Menezes (2003) estudando o efeito do aumento da concentração de PEG-6000 sobre o efeito germinativo de soja, observaram um decréscimo da germinação de soja com acréscimo na concentração de PEG-6000. Resultados semelhantes foram observados por Braccini et al. (1996), em um estudo com quatro cultivares de soja.

O comprimento da parte aérea decresceu de acordo com o aumento das concentrações de PEG (Figura 4). 
Figura 4. Comprimento da parte aérea das plântulas $(\mathrm{cm})$ de Physalis peruviana submetidas a diferentes estresses hídricos e induzidas com PEG-6000.

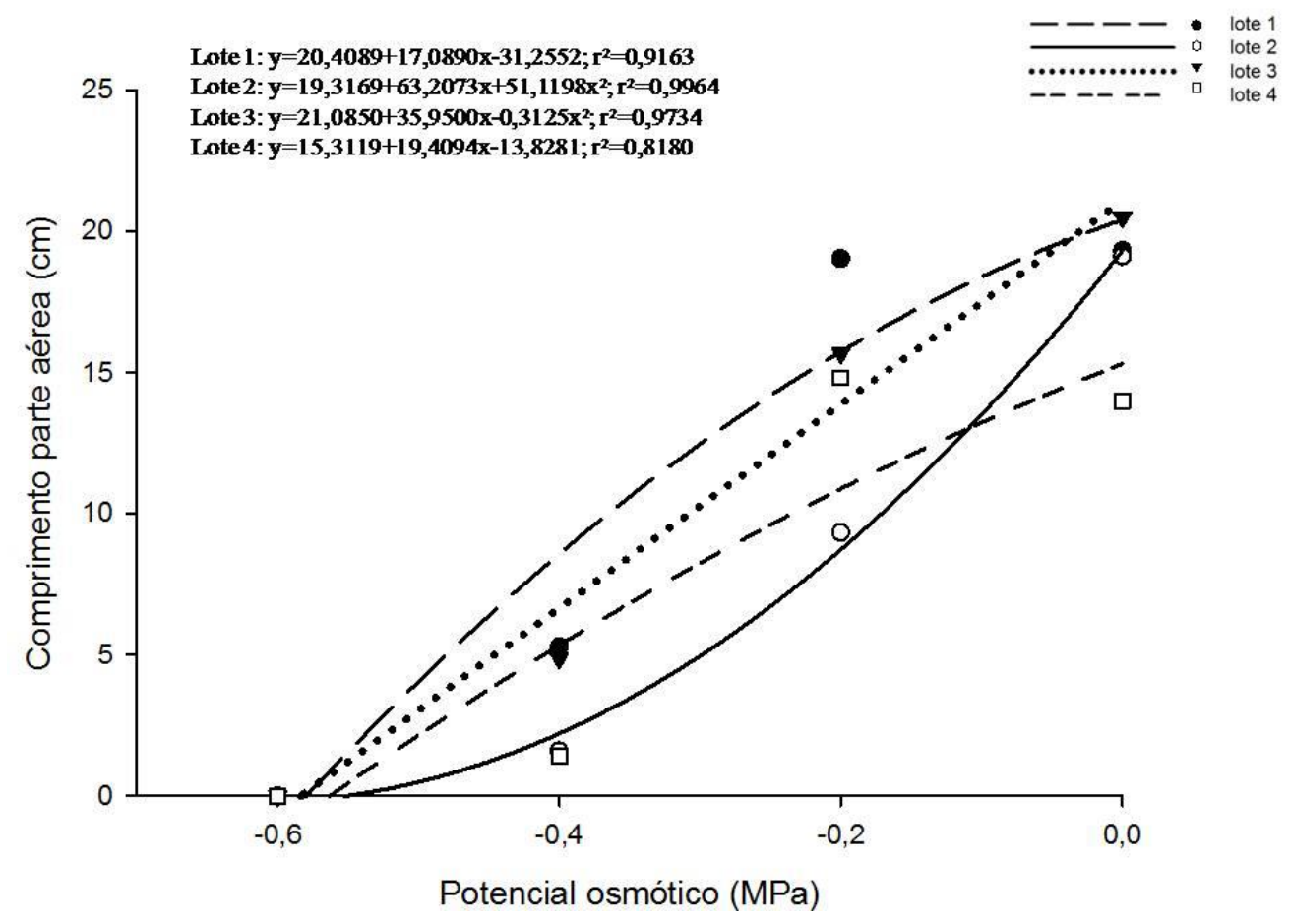

Fonte: Autores (2022).

A mesma tendência foi observada por Torres (1996) em estudo com pimentão (Capsicum annum L.), no qual encontrou que em condições de campo, a diminuição do potencial osmótico leva a uma redução do comprimento das plântulas. Adicionalmente, Vaz-de-Melo, Santos, Finoto, Dias e Alvarenga (2012) observaram comportamento semelhante em milho de pipoca, no qual o comprimento da parte aérea decresceu com o aumento das concentrações dos potenciais osmóticos.

Ao avaliar o vigor das sementes pelo comprimento radicular, foi possível observar que todos os lotes tiveram baixo desenvolvimento radicular no controle. Quando submetidos ao potencial -0,2 MPa, verificou-se que todos os lotes responderam de maneira positiva com alto comprimento radicular (Figura 5). 
Figura 5. Comprimento da raiz das plântulas $(\mathrm{cm})$ de Physalis peruviana submetidas a diferentes estresses hídricos, induzidas com PEG-6000.

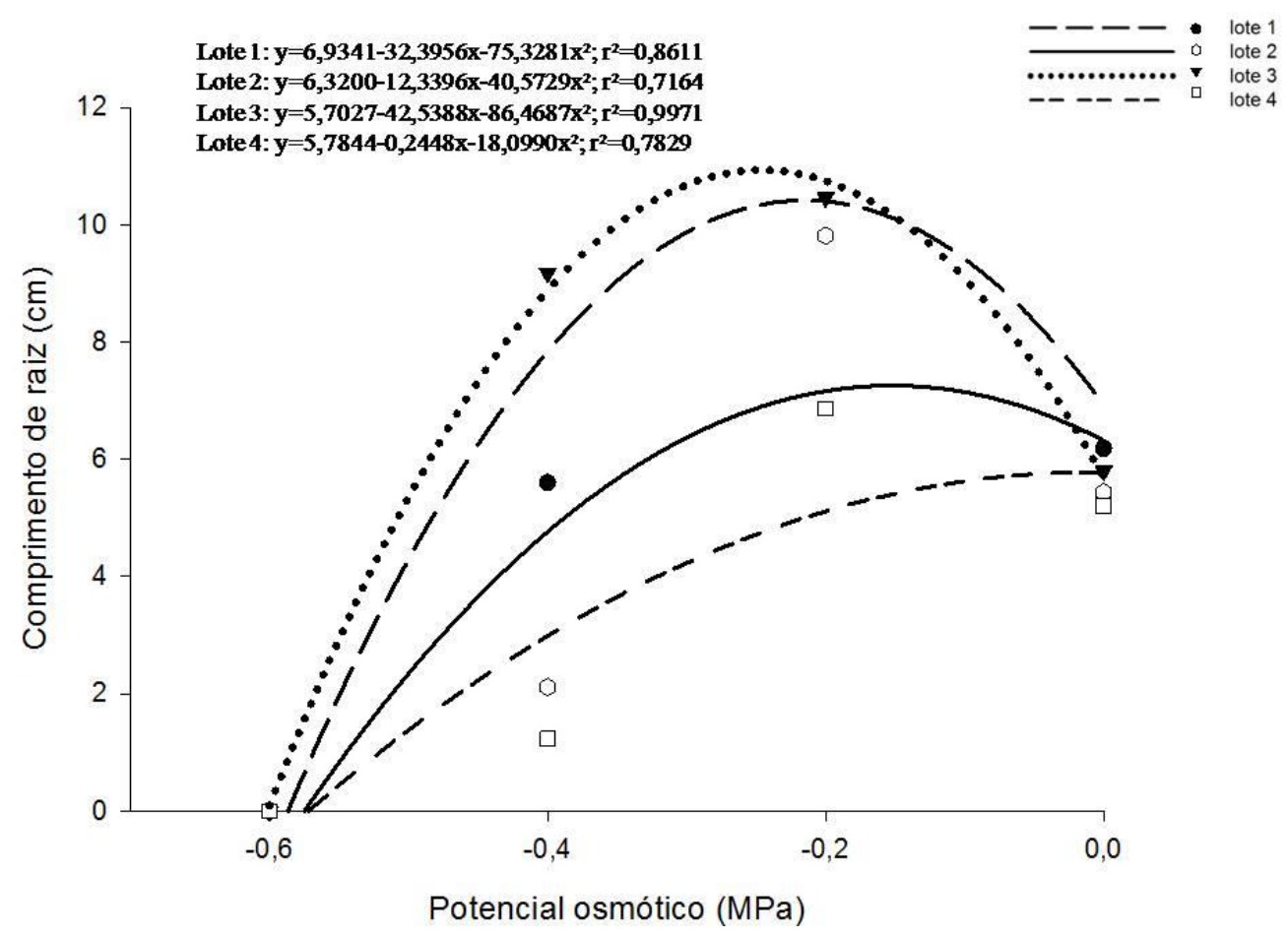

Fonte: Autores (2022).

Quando sementes são expostas ao estresse hídrico tendem a desenvolver maior sistema radicular para alcançarem regiões mais profundas do solo em busca de água para absorver. Ávila et al. (2007) encontraram resultados semelhantes em estudos com sementes de canola submetidas até o potencial osmótico -0,47 MPa de manitol. No presente estudo, os lotes de sementes 1, 2 e 4 no potencial osmótico -0,6 MPa não emitiram radícula, exceto o lote 3 que apresentou desenvolvimento da radicular.

\section{Conclusão}

Lotes de maior qualidade fisiológica de sementes de $P$. peruviana apresentaram melhor desempenho sob estresse hídrico induzido por PEG 6000 até o potencial -0,2 MPa. A restrição hídrica provocou um menor crescimento da parte aérea das plântulas, no entanto, quando as sementes foram submetidas ao potencial - $0,2 \mathrm{MPa}$, verificou-se um aumento no comprimento radicular.

Sabe-se que as culturas respondem as conduções adversas através de adaptações morfofisiológicas, sendo que essas possíveis adaptações podem interferir de maneira distinta na produção. Com isso, são necessárias mais pesquisas para verificar como o estresse hídrico pode afetar a produtividade da cultura.

\section{Referências}

Adegbuyi, E., Cooper, S. R. \& Don, R. (1981). Osmotic priming of some herbage grass seed using polyethylene glycol (PEG). Seed Science and Technology, 9(3), 867- 878 .

Ávila, M. R., Braccini, A. L., Scapim, C. A., Fagliari, J. R., \& Santos, J. L. (2007). Influência do estresse hídrico simulado com manitol na germinação de sementes e crescimento de plântulas de canola. Revista Brasileira de Sementes. 29(1), 98-106. https://doi.org/10.1590/S0101-31222007000100014. 
Barbosa, R. M., Costa, D. S. \& Sá, M. E. (2011). Envelhecimento acelerado de sementes de espécies oleráceas. Pesquisa Agropecuária Tropical, 41(3), 328335. https://doi.org/10.5216/part.v41i3.9738.

Basha, P. O., Sudarsanam, G., Reddy, M. M. S. \& Sankar, N. S. (2015). Effect of PEG induced water stress on germination and seedling development of tomato germplasm. International Journal of Recent Scientific Reseach, 6(5), 4044-4049. http://www.recentscientific.com/sites/default/files/2471.pdf.

Black, R. A. \& El Hadi, F. M. (1992). Presowing treatments of Acacia senegal seed: germination and growth. Tropical Agricultural, 69(1), 15-20.

Braccini, A. L., Ruiz, H. A., Braccini, M. C. L. \& Reis, M. S. (1996). Germinação e vigor de sementes de soja sob estresse hídrico induzido por soluções de cloreto de sódio, manitol e polietileno glicol. Revista Brasileira de Sementes, 18(1), 10-16. http://dx.doi.org/10.17801/0101-3122/rbs.v18n1p10-16.

Braga, N. S. (2010). Avaliação fisiológica de sementes de pinhão manso. Dissertação de mestrado. Universidade Federal Rural do Rio de Janeiro, Seropédica, RJ, Brasil.

Brasil. (2009). Ministério da Agricultura, Pecuária e Abastecimento. Regras para análise de sementes. Brasília, DF. https://www.gov.br/agricultura/ptbr/assuntos/insumos-agropecuarios/arquivos-publicacoes-insumos/2946_regras_analise_sementes.pdf.

Carvalho, T. C. D., D'Angelo, J. W. D. O., Scariot, G. N., Saes Júnior, L. A. \& Cuquel, F. L. (2014). Germinação de sementes de Physalis angulata L.: estádio de maturação do cálice e forma de armazenamento. Pesquisa Agropecuária Tropical, 44(4), 357-362. https://www.revistas.ufg.br/pat/article/view/26628/17486.

Chaves, A. C., Schuch, M. W. \& Erig, A. C. (2005). Estabelecimento e multiplicação in vitro de Physalis peruviana L. Revista Ciência Agrotécnica, 29(6), 1281-1287. https://doi/org/10.1590/S1413-70542005000600024.

Costa, P. R., Custódio, C. C., Machado Neto, N. B. \& Marubayashi, O. M. (2004). Estresse hídrico induzido por manitol em sementes de soja de diferentes tamanhos. Revista Brasileira de Sementes, 26(1), 105-113. https://doi.org/10.1590/S0101-31222004000200015.

Diniz, F. O., Chamma, L. \& Novembre, A. D. L. C. (2020). Germinação de sementes de Physalis peruviana L. em diferentes condições de temperatura, luz e substrato. Revista Ciência Agronômica, 51(1), e20166493. https://doi.org/10.5935/1806-6690.20200003.

Filgueira, F. A. R., Obeid, P. C., Morais, H. J., Santos, W. V. \& Fontes, R. R. (1999). Tomate tutorado. In.: A. C. Ribeiro, P. T. G. Guimarães, V. H. Alvarez V. (Eds.). Recomendações para o uso de corretivos e fertilizantes em Minas Gerais - $5^{a}$ Aproximação. (pp. 207-208). Comissão de Fertilidade do Solo do Estado de Minas Gerais - CFSEMG.

Fischer, G. \& Martínez, O. (1999). Calidad y madurez de la uchuva (Physalis peruviana L.) enrelación conlacoloración del fruto. Agronomía colombiana, 16(1-3), 35-39. https://revistas.unal.edu.co/index.php/agrocol/article/view/25079/25612.

Hadas, A. A. (1977). A suggested method for testing vigor under water stress in simulated arid condition. Seed Science and Technology, 5(3), 527-537.

Hobbs, P. R. \& Oberndorf, R. L. (1972). Interaction of initial seed moisture and imbibitional temperature on germination and productivity of soybean. Crop Science, 12(5), 664-667. https://doi.org/10.2135/cropsci1972.0011183X001200050033x.

Lechinoski, A., Freitas, J. M. N., Castro, D. S., Lobato, A. K. S., Oliveira Neto, C. F., Cunha, R. L. M. \& Costa, R. C. L. (2007). Influência do estresse hídrico nos teores de proteínas e aminoácidos solúveis totais em folhas de teca (Tectona grandis L. f). Revista Brasileira de Biociências, 5(S2), 927-929. http://www.ufrgs.br/seerbio/ojs/index.php/rbb/article/view/755/632.

Moraes, G. A. F. \& Menezes, N. L. (2003). Desempenho de sementes de soja sob condições diferentes de potencial osmótico. Ciência Rural, 33(2), 219-226. https://doi.org/10.1590/S0103-84782003000200007.

Moterle, L. M., Lopes, P. C., Braccini, A. L. \& Scapim, C. A. (2006). Germinação de sementes e crescimento de plântulas de cultivares de milho-pipoca submetidas ao estresse hídrico e salino. Revista Brasileira de Sementes, 28(3), 169-176. https://doi.org/10.1590/S0101-31222006000300024.

Nascimento, W. M. (1998). Condicionamento osmótico de sementes de hortaliças: potencialidades e implicações. Horticultura Brasileira, 16(2), 106-109. https://doi.org/10.1590/S0102-053619980000200002.

Oro, P., Villa, F., Dartora, J., Marini, D., Matiello, V. D. \& Favorito, P. A. (2012). Metodologia para teste de envelhecimento acelerado em sementes de fisális (Physalis peruviana). Cultivando o Saber, 5(3), 167-175. https://cultivandosaber.fag.edu.br/index.php/cultivando/article/view/465/375.

Pastori, G. M. \& Foyer, C. H. (2002). Common components, networks, and pathways of cross-tolerance to stress. The central role of "redox" and abscisic acid-mediated controls. Plant Physiology, 129(2), 460-468. https: 10.1104/pp.011021.

Pellizzaro, V., Omura, M. S., Furlan, F. F., Costa, D. S., Ponce, R. M., Freiria, G. H., Ibanhes Neto, H. F. \& Takahashi, L. S. A. (2019). Physiological potential of Physalis peruviana L. seeds under different temperatures and light wavelengths. Semina: Ciências Agrárias, 40(5), 1737-1746. https://www.uel.br/revistas/uel/index.php/semagrarias/article/view/30087/25632.

Rahimi, A. (2013). Seed priming improves the germination performance of cumin (Cuminum syminum L.) under temperature and water stress. Industrial Crop and Products, 42(1), 454-460. 10.1016/j.indcrop.2012.06.026.

Rufato, A. R., Rufato, L., Lima, C. S. \& Muniz, J. (2013). A cultura da Physalis. In: A. A. Kretzschmar, L. Rufato, T. R. Pelizza (Orgs.) Pequenas frutas. (pp. 143-193). Embrapa Uva e Vinho (CNPUV).

Rutz, J. K., Voss, G. B., Jacques, A. C., Pertuzatti, P. B., Barcia, M. T. \& Zambiazi, R. C. (2012). Geléia de Physalis peruviana L.: Caracterização bioativa, antioxidante e sensorial. Alimentos e Nutrição, 23(3), 369-375. http://serv-bib.fcfar.unesp.br/seer/index.php/alimentos/article/view/369/1957.

Silva, M. C. C., Medeiros, A. F. A., Dias, D. C. F. S., Alvarenga, E. M., Coelho, F. S. \& Braun, H. (2011). Efeito do estresse hídrico e térmico na germinação e no vigor de sementes de cenoura. Idesia, 29(3), 39-44. http://dx.doi.org/10.4067/S0718-34292011000300006. 
Research, Society and Development, v. 11, n. 2, e44011225997, 2022

(CC BY 4.0) | ISSN 2525-3409 | DOI: http://dx.doi.org/10.33448/rsd-v11i2.25997

Souza, C. L. M., Souza, M. O., Oliveira, M. F., Oliveira, L. M. \& Pelacani, C. R. (2010). Morfologia de sementes e desenvolvimento pós-seminal de Physalis angulata L. Acta Botanica Brasilica, 24(4), 1082-1085. https://doi.org/10.1590/S0102-33062010000400023.

Souza, C. L. M., Souza, M. O., Oliveira, R. S. \& Pelacani, C. R. (2016). Physalis peruviana seed storage. Revista Brasileira de Engenharia Agrícola e Ambiental, 20(3), 263-268. https://doi.org/10.1590/1807-1929/agriambi.v20n3p263-268.

Sun, W. Q. \& Leopold, A. C. (1997). Cytoplasmic vitrification and survival of anhydrobiotic organisms. Comparative Biochemistry and Physiology, 117A(3), 327-333.

Tambelini, M. \& Perez, S. C. J. G. A. (1998). Efeitos do estresse hídrico simulado com PEG (6000) ou manitol na germinação de sementes de barbatimão (Stryphnodendron polyphyllum Mart.). Revista Brasileira de Sementes, 20(1), 226-232.

Teixeira, R. N., Toledo, M. Z., Ferreira, G., Cavarini, C. \& Jasper, S.P. (2011). Germinação e vigor de sementes de crambe sob estresse hídrico. Irriga, 16(1), 42-52. https://irriga.fca.unesp.br/index.php/irriga/article/download/190/99.

Torres, S. B. (1996). Qualidade fisiológica de sementes de pimentão (Capsicum annuum L.) através do teste de estresse hídrico. Revista Brasileira de Sementes, 18(2), 246-250.

Vale, N. M., Barili, L. D., Rozzeto, D. S., Coimbra, J. L., Guidolin, A. F. \& Köop, M. M. (2012). Avaliação para tolerância ao estresse hídrico em feijão. Biotemas, 25(3), 135-144. https://doi.org/10.5007/2175-7925.2012v25n3p135.

Vaz-de-Melo, A., Santos, L. D. T., Finoto, E. F., Dias, D. C. F. S., \& Alvarenga, E. M. (2012). Germinação e vigor de sementes de milho-pipoca submetidas ao estresse térmico e hídrico. Bioscience Journal, 28(5), 687-695. https://seer.ufu.br/index.php/biosciencejournal/article/view/11669.

Villela, F. A., Doni Filho, L., Sequeira, E. L. (1991). Tabela de potencial osmótico em função da concentração de polietileno glicol 6.000 e da temperatura. Pesquisa Agropecuária Brasileira, 26(11/12), 1957-1968. https://ainfo.cnptia.embrapa.br/digital/bitstream/AI-SEDE/21308/1/pab18_novdez_91.pdf.

Yoon, B., Lang, H. J. \& Cobb, B. G. (1997). Priming with salt solutions improves germination of pansy seed at high temperatures. HortScience, 32(2), 248250. https://doi.org/10.21273/HORTSCI.32.2.248.

Zapata, J. L., Saldarriga, A., Londoño, M. \& Dias, C. (2002). Manejo del cultivo dela uchuva en Colombia. Corporación Colombiana de Investigación Agropecuaria (CORPOICA). Rionegro, Antioquia: Colombia. 